\title{
Is HLA-B27 Increased in Patients Diagnosed with Undifferentiated Arthritis? Results from the Leiden Early Arthritis Cohort
}

\author{
Floris van Gaalen, Rosaline van den Berg, Inge Verhoog, Joris Schonkeren, \\ Annette van der Helm-van Mil, Tom Huizinga, and Désirée M. van der Heijde
}

\begin{abstract}
Objective. Undifferentiated arthritis (UA) is a common form of arthritis. According to the Assessment of Spondyloarthritis international Society (ASAS) criteria for peripheral spondyloarthritis (pSpA), HLA-B27 can be used to help classify patients with pSpA. We tested whether HLA-B27 is increased in patients diagnosed with UA.

Methods. Prevalence of HLA-B27 was compared between healthy controls and patients with UA. SpA features were compared between HLA-B27-positive and -negative UA, and SpA.

Results. We found $10.1 \%$ of UA (38/375) versus 7.2\% (403/5584) of controls were HLA-B27-positive (OR 1.5, 95\% CI 1.0-2.1; p = 0.037). HLA-B27-positive patients with UA had more SpA features than HLA-B27-negative patients (mean 1.6, SD 1.0, and 0.9 SD 0.6; $p<0.001$ ), but patients with SpA had significantly more SpA features (mean 4.5, SD 1.5; p < 0.001). Family history and preceding infection were features more common in HLA-B27-positive than in HLA-B27-negative UA $(15.8 \%$ vs $1.3 \%, p=0.04$ and $15.8 \%$ vs $2.6 \%, p=0.04)$. After HLA-B27 testing, 21 additional patients $(5.6 \%)$ with UA could potentially have been classified with pSpA according to the ASAS criteria.

Conclusion. HLA-B27 is more common in patients with UA than in controls. However, the yield of HLA-B27 testing in UA is low. Our results suggest that HLA-B27 testing should be reserved for patients with additional SpA features. (First Release Aug 15 2014; J Rheumatol 2014; 41:1948-51; doi:10.3899/jrheum.131462)
\end{abstract}

Key Indexing Terms:

HLA-B27

SPONDYLOARTHRITIS

Spondyloarthritis $(\mathrm{SpA})$ refers to a group of common related rheumatic diseases, including ankylosing spondylitis, psoriatic arthritis, reactive arthritis, inflammatory bowel disease (IBD)-related spondylitis and arthritis, and undifferentiated $\mathrm{SpA}$. The clinical presentation of $\mathrm{SpA}$ is heterogeneous, and no single distinguishing feature exists for all forms of $\mathrm{SpA}^{1}$. However, various clinical laboratory and imaging features suggestive of SpA are known and form the building blocks for classification criteria for $\mathrm{SpA}$ and diseases in the SpA spectrum.

SpA can be distinguished by its clinical presentation as predominantly axial $\mathrm{SpA}$ (axSpA; e.g., inflammation of the spine and/or sacroiliac joints) or peripheral SpA (pSpA; e.g.,

From the Department of Rheumatology, Leiden University Medical Centre, Leiden, the Netherlands.

The work of F. van Gaalen is supported by Tracer, a Centre for Translational Molecular Medicine project.

F. van Gaalen, MD, PhD; R. van den Berg, MSc; I. Verhoog, BSc; J. Schonkeren, BSc; A. van der Helm-van Mil, MD, PhD; T. Huizinga, $M D, P h D ; D . M$. van der Heijde, MD, PhD, Department of Rheumatology, Leiden University Medical Centre.

Address correspondence to Dr. F. van Gaalen, Department of

Rheumatology, Leiden University Medical Centre, C4-R, PO Box 9600,

Leiden 2300 R, The Netherlands.E-mail:f.a.van_gaalen@lumc.nl

Accepted for publication June 18, 2014.

\section{GENETIC RISK FACTORS UNDIFFERENTIATED ARTHRITIS}

arthritis, dactylitis, and/or enthesitis) and classified with 2 criteria sets developed by the Assessment of SpondyloArthritis international Society (ASAS). In patients with early arthritis, the ASAS pSpA criteria performed well with a good specificity at a reasonable sensitivity ${ }^{2}$.

According to the ASAS criteria for pSpA, HLA-B27 can be used to help classify patients with $\mathrm{pSpA}^{3}$. While in adults HLA-B27 is better known for its association with axSpA rather than $\mathrm{pSpA}^{4}$, we recently showed that in a large cohort of patients presenting with arthritis, HLA-B27 was significantly more common in patients with $\mathrm{SpA}$ than in patients without $\mathrm{SpA}^{2}$.

Undifferentiated arthritis (UA) is defined as an inflammatory arthritis in which no definitive diagnosis can be made. Inception cohorts from Europe and North America have shown that UA is common and may even be seen more frequently than rheumatoid arthritis (RA). Estimates of the percentage of patients diagnosed with UA range from $23 \%$ to $81 \%$ of early arthritis cohorts ${ }^{5}$. UA spans a wide spectrum of conditions with various natural courses. Some patients will have a benign, self-limiting disease course while others will experience disease persistence including development of destructive arthritis ${ }^{6}$. There are limited data on the preva-

Personal non-commercial use only. The Journal of Rheumatology Copyright @ 2014 . All rights reserved. 
lence of HLA-B27 in UA but 1 study has reported an HLA-B27 prevalence of $16 \%$ in 75 patients with UA compared to $7 \%$ in controls ${ }^{7}$. This suggests that HLA-B27 is increased in UA and using the new ASAS pSpA criteria, HLA-B27 could be used to classify a proportion of UA as pSpA. Further, based on clinical experience, the $3 \mathrm{e}$ Initiative in Rheumatology recommends testing HLA-B27 in UA when $\mathrm{SpA}$ is suspected ${ }^{8}$. The aim of our study is to test the prevalence of HLA-B27 in a large cohort of patients with UA and to assess whether HLA-B27 testing is useful in patients with UA.

\section{MATERIALS AND METHODS}

Patients and data. Patients in our study were all participants of the Leiden Early Arthritis cohort (EAC). The EAC has been described extensively ${ }^{9}$. In short, the EAC is a population-based prospective cohort including patients with suspected arthritis with a symptom duration $<2$ years referred by physicians to the rheumatology outpatient clinic of the Leiden University Medical Center to detect and treat rheumatic diseases in an early state 9 . Between February 1993 and February 2009, 2285 patients were included. All patients underwent an extensive analysis including but not limited to urinalysis, radiographs of affected joints and chest, and blood analysis of, among other things, acute-phase reactants, uric acid, creatinine, IgM-rheumatoid factor (RF), and anticitrullinated protein antibodies. Treating physicians were free to order any additional tests outside the protocol. Followup visits with standard clinical assessments were performed 3 months after the first presentation and yearly thereafter. Radiographs of the hands and feet were taken at baseline and yearly thereafter.

At the 1-year followup visit, according to the diagnosis of the treating rheumatologist, UA was found in 674 patients (29.5\%). RA was diagnosed in 973 patients $(42.6 \%)$ and $\mathrm{SpA}$ in 226 patients $(9.9 \%)$. SpA features of the 226 patients with $\mathrm{SpA}$ have been reported ${ }^{2}$. The remaining 412 patients $(18 \%)$ had a large variety of diagnoses including systemic lupus erythematosus, osteoarthritis, gout, and infectious arthritis.

Data taken from the EAC database included age at inclusion, sex, localization of arthritis, the number and the pattern of affected joints (e.g., symmetric or asymmetric arthritis), erythrocyte sedimentation rate, C-reactive protein, and IgM-RF. HLA-B27 testing was not part of the study protocol. However, doctors were able to request it when they considered it necessary. Chart review showed that none of the patients with UA were typed for HLA-B27 prior to our study.

HLA-B27 testing. For our study, HLA-B27 was typed in all patients with UA using available DNA $(n=375)$. The remaining 299 patients with UA were not HLA-B27 typed: DNA samples of 89 patients were of insufficient quality or had been depleted and in 210 patients with UA, no samples had ever been stored because DNA sampling was only implemented a few years after the start of the cohort. HLA-B27 typing was performed with sequence-specific primers on genomic DNA with real-time polymerase chain reaction using SYBR Green. In a total volume of $7 \mu 112.5 \mathrm{ng}$, gDNA was mixed with $3.5 \mu 1$ iQ SYBR Green Supermix (Biorad Laboratories) and $100 \mathrm{nM}$ of both forward primer (5'-GCT ACG TGG ACG ACA CGC T) and reverse primer (5'-GCG CCC GCG GCT CCT $\mathrm{CT}$ ). Reactions were performed in a CFX-384 thermocycler (Biorad Laboratories) with the following protocol: $95.0^{\circ} \mathrm{C}$ for $3 \mathrm{~min}$ followed by 40 amplification cycles $\left(95.0^{\circ} \mathrm{C}\right.$ for $0: 10 ; 71.0^{\circ} \mathrm{C}$ for $\left.0: 25\right)$; standard melting curves ${ }^{10}$. Results of HLA-B27 typing of 5584 blood donors who served as healthy controls were used for comparison ${ }^{11}$.

SpA features. To compare SpA features between HLA-B27-positive and HLA-B27-negative patients with UA, a nested case-control analysis was performed. In total, 38 patients with UA were HLA-B27-positive. Each HLA-B27-positive patient with UA was matched to 2 HLA-B27-negative patients with UA $(n=76)$ based on age at inclusion and sex $(p=0.6$ and $\mathrm{p}=1.00$, respectively). Charts from these 114 patients (from baseline to 1-yr followup) were searched for additional $\mathrm{SpA}$ features as mentioned in the following criteria sets: Amor criteria, European Spondyloarthropathy Study Group criteria, ASAS pSpA criteria for $\mathrm{pSpA}$, and ClASsification criteria for Psoriatic ARthritis (CASPAR) criteria ${ }^{3,12,13,14}$. These features are family history for SpA, inflammatory back pain (IBP), psoriasis, dactylitis, enthesitis, uveitis, IBD, preceding infection (urethritis/cervicitis or diarrhea within $1 \mathrm{mo}$ before the onset of arthritis/dactylitis/enthesitis), sacroiliitis on imaging (radiograph and/or MRI), a good response to nonsteroidal antiinflammatory drugs, RF negativity, and juxtaarticular new bone formations $33,12,13,14$.

Statistical analysis. Crosstab analysis expressed in OR was used to study the frequency of HLA-B27 in patients with UA and SpA, and in controls. Throughout the study, chi-squared tests were used for dichotomous variables and Mann-Whitney U tests for continuous variables. Wilcoxon signed-rank test and McNemar's test were used for matched samples. SPSS 20.0 and Epi Info was used for analyses and graphs. P values $<0.05$ were considered significant.

\section{RESULTS}

Of the 375 HLA-B27-typed patients with UA, 173 (46\%) presented with a monoarthritis, $116(31 \%)$ with oligoarthritis, and 86 (23\%) with polyarthritis (Table 1). Of the patients with UA, 38/375 (10.1\%) were HLA-B27-positive compared to $403 / 5584$ Dutch blood donors (7.2\%). This gave an OR of 1.5 (95\% CI $1.0-2.1 ; \mathrm{p}=0.037)$. In comparison, 48/186 (25.8\%) of patients with SpA (Table 2) were HLA-B27-positive (OR 4.5: 95\% CI 3.2-6.3; p < 0.001 compared to healthy controls).

The 3 most frequently reported $\mathrm{SpA}$ features in the 114 patients with UA in the nested cases-control analysis were enthesitis $(11.4 \%)$, psoriasis $(8.8 \%)$, and a preceding infection (7\%), in addition to RF negativity (72.8\%). Family history $(\mathrm{p}=0.04)$ and preceding infection $(\mathrm{p}=0.04)$ were more common in HLA-B27-positive patients with UA than in HLA-B27-negative patients with UA. No significant differences were found for other SpA features, in the arthritis pattern (Table 2), or the number of affected joints (data not shown).

Overall, HLA-B27-positive patients with UA had more SpA features (mean 1.6; SD 1.0) than did

Table 1. Baseline characteristics of 375 HLA-B27 typed patients with undifferentiated arthritis.

\begin{tabular}{lc} 
Characteristic & \\
\hline Age at inclusion, mean (SD) & $50.5(16.5)$ \\
Male, $\mathrm{n}(\%)$ & $147(39.2)$ \\
Symptom duration, weeks (range) & $16(0-79)$ \\
ESR, mean (SD) & $24.7(24.1)$ \\
CRP, mean (SD) & $17.0(27.6)$ \\
Number of affected joints, mean (range) & $2.5(1-14)$ \\
Arthritis pattern & \\
Monoarthritis, $\mathrm{n}(\%)$ & $173(46)$ \\
Oligoarthritis, $\mathrm{n}(\%)$ & $116(31)$ \\
Polyarthritis, $\mathrm{n}(\%)$ & $86(23)$ \\
HLA-B27 positivity, $\mathrm{n}(\%)$ & $38(10.1)$
\end{tabular}

ESR: erythrocyte sedimentation rate; CRP: C-reactive protein. Personal non-commercial use only. The Journal of Rheumatology Copyright @ 2014 . All rights reserved. 
Table 2. Clinical characteristics of 38 HLA-B27-positive patients with undifferentiated arthritis (UA) and 76 age-matched and sex-matched HLA-B27-negative patients with UA, and 226 patients with spondyloarthritis (SpA). Data are n (\%) unless otherwise indicated.

\begin{tabular}{|c|c|c|c|c|c|}
\hline & $\begin{array}{c}\text { HLA-B27+ } \\
\text { Patients with UA, } \\
n=38\end{array}$ & $\begin{array}{c}\text { HLA-B27- } \\
\text { Patients with UA, } \\
n=76\end{array}$ & $\begin{array}{c}\text { Patients } \\
\text { with } \mathrm{SpA}, \\
\mathrm{n}=226\end{array}$ & $\begin{array}{l}\mathrm{p} \text { (patients with } \\
\text { UA HLA-B27+ } \\
\text { vs HLA-B27-) }\end{array}$ & $\begin{array}{l}\mathrm{p} \text { (patients with } \\
\text { UA HLA-B27+ } \\
\text { vs SpA) }\end{array}$ \\
\hline Age, yrs, mean (SD) & $48(16.2)$ & $48.2(16.0)$ & $43.7(15.0)$ & 0.6 & 0.11 \\
\hline Male & $15(39.5)$ & $30(39.5)$ & $123(54.4)$ & 1.0 & 0.09 \\
\hline \multicolumn{6}{|l|}{ Arthritis pattern } \\
\hline Monoarthritis & $14(36.8)$ & $22(28.9)$ & $51(24.9)$ & & \\
\hline Oligoarthritis & $17(44.7)$ & $34(44.7)$ & $74(36.1)$ & $0.25^{\#}$ & $0.02^{\#}$ \\
\hline Polyarthritis & $7(18.4)$ & $20(26.3)$ & $80(39.0)$ & & \\
\hline Family history & $6(15.8)$ & $1(1.3)$ & $169(74.7)$ & 0.04 & $<0.001$ \\
\hline Inflammatory back pain & $2(5.3)$ & $0(0)$ & $35(15.5)$ & 0.25 & 0.09 \\
\hline Psoriasis & $6(15.8)$ & $4(5.3)$ & $145(64.2)$ & 0.13 & $<0.001$ \\
\hline Dactylitis & $2(5.3)$ & $1(1.3)$ & $60(30.2)$ & 0.13 & $<0.001$ \\
\hline Enthesitis & $6(15.8)$ & $7(9.2)$ & $40(17.7)$ & 0.11 & 0.77 \\
\hline Asymmetric lower limb arthritis & $7(18.4)$ & $12(15.8)$ & $64(28.3)$ & 0.31 & 0.20 \\
\hline Uveitis & $2(5.3)$ & $0(0)$ & $8(3.5)$ & & 0.61 \\
\hline Inflammatory bowel disease & $0(0)$ & $0(0)$ & $12(5.3)$ & - & 0.26 \\
\hline History of preceding infection & $6(15.8)$ & $2(2.6)$ & $38(16.8)$ & 0.04 & 0.88 \\
\hline Sacroiliitis on imaging & $0(0)^{*}$ & $0(0) * * *$ & $12(20.6)^{\S}$ & - & 0.38 \\
\hline RF-negative & $30(78.9) * *$ & $53(69.7)$ & $200(91.7)$ & 0.06 & 0.02 \\
\hline Good response to NSAID & $1(2.6)$ & $0(0)$ & $7(3.1)$ & 0.32 & 0.88 \\
\hline Juxtaarticular bone formation & $0(0)$ & $0(0)$ & $19(8.4)$ & & 0.13 \\
\hline $\mathrm{CRP}, \mathrm{mg} / \mathrm{l}$, mean $(\mathrm{SD})$ & $10.3(11.4)$ & $14.8(24.5)$ & $26.6(35.6)$ & 0.16 & $<0.001$ \\
\hline $\mathrm{ESR}, \mathrm{mm} / \mathrm{h}$, mean $(\mathrm{SD})$ & $23.1(23.7)$ & $23.0(20.6)$ & $33.5(29.7)$ & 0.99 & 0.02 \\
\hline No. SpA features ${ }^{\# \#}$, mean (SD) & $1.6(1.0)$ & $0.9(0.6)$ & $4.5(1.5)$ & $<0.001$ & $<0.001$ \\
\hline
\end{tabular}

\# Comparing polyarthritis versus non-polyarthritis. \#\# Not including HLA-B27. *** Tested in 14 patients. * Tested in 6 patients. ** Tested in 37 patients.

$\S$ Tested in 58 patients. Numbers in bold face are statistically significant. ESR: erythrocyte sedimentation rate; CRP: C-reactive protein; NSAID: nonsteroidal antiinflammatory drugs.

HLA-B27-negative patients with UA (mean 0.9; SD 0.6; $\mathrm{p}<0.001$; Table 2).

In the HLA-B27-positive UA group, 4/38 (10.5\%) had no additional SpA features, 16/38 (42.1\%) had 1 additional SpA feature, 10/38 (26.3\%) had $2 \mathrm{SpA}$ features, 7/38 $(18.4 \%)$ had $3 \mathrm{SpA}$ features, and $1 / 38$ (2.6\%) had 4 additional SpA features. In the HLA-B27-negative UA group, 16/76 (21.1\%) had no SpA features, 53/76 (69.7\%) had 1 SpA feature, 6/76 (7.9\%) had 2 SpA features, and 1/76 $(1.3 \%)$ had 3 SpA features.

Before HLA-B27 testing, 23/114 patients (20.2\%) with UA fulfilled the ASAS pSpA criteria; 17 were HLA-B27-positive and 6 HLA-B27-negative. The most common $\mathrm{SpA}$ features resulting in a classification were psoriasis and a preceding infection. After HLA-B27 testing, 38 HLA-B27-positive patients with UA met these criteria, including the 17 patients that already met the ASAS pSpA criteria before testing. It is noteworthy that 7 HLA-B27-positive patients with UA did not have any other SpA features and had an arthritis pattern that was not asymmetric nor localized in the lower limb.

Given these results, we analyzed whether an asymmetric arthritis of the lower limb by itself would have given a higher percentage of HLA-B27 positivity in UA instead of testing all patients with UA. Sixty-four out of 375 patients with UA had symmetric lower limb arthritis. Only 7/64 $(10.1 \%)$ were HLA-B27-positive, the same percentage as in the entire group of patients with UA $(p=0.7)$.

Next, we compared the number of $\mathrm{SpA}$ features in the HLA-B27-positive patients with UA to the number of SpA features in patients with SpA (mean 4.5; SD 1.5). The result was statistically significantly higher in the latter group $(\mathrm{p}<$ 0.001 ). In patients with SpA, family history for SpA, IBP, psoriasis, and dactylitis were all more common than in HLA-B27-positive patients with UA $(\mathrm{p}<0.001)$ as well as RF negativity $(p=0.02$; Table 2$)$. Age and sex were not different between the UA and SpA groups. Patients with SpA more often presented with a polyarthritis than did patients with UA [80/205 (39\%) and 7/38 (18.4\%) respectively; $\mathrm{p}=0.02]$.

\section{DISCUSSION}

The prevalence of HLA-B27 in UA is higher than in controls. Although the results are statistically significant, the increase in HLA-B27 positivity in UA is modest at best (10.1\% HLA-B27 positivity in UA compared to $7.2 \%$ in controls). This percentage is lower than the $16 \%(12 / 75$ patients) reported in a previous study in patients with $\mathrm{UA}^{7}$. This could be because the EAC is a longstanding cohort and we have analyzed patients from 1993 to 2009. Physicians'

Personal non-commercial use only. The Journal of Rheumatology Copyright @ 2014 . All rights reserved. 
perceptions may change over time and this may be particularly relevant in diagnosing UA and SpA.

Classification criteria are not the same as diagnostic criteria. A clear example of the difference between diagnosis and classification is found in our cohort, where before HLA-B27 testing, 21 patients with UA met the ASAS classification criteria for $\mathrm{pSpA}$ but the clinical diagnosis was UA.

Classification criteria may influence clinical practice. This is one of the reasons we chose to study patients with UA included before 2010, because the new American College of Rheumatology/European League Against Rheumatism criteria for RA were published in 2010 and the ASAS pSpA criteria in 2011. Data from the Leiden EAC show that when the 2010 RA criteria are used as diagnostic criteria instead of the 1987 RA criteria, the number of patients with UA drops 33\%, thereby potentially influencing what is considered as UA in daily practice ${ }^{15}$.

A limitation of this study was that not all patients with UA could be typed for HLA-B27. However, the reason for absence of DNA was not related to the outcome of the study and we found no differences in baseline characteristics between patients tested and not tested for HLA-B27 (data not shown).

Unfortunately, because the number of physicians working in the EAC over the years is large, it was not feasible to ask physicians if they would change their diagnosis based on the results of the HLA-B27 typing. Nevertheless, given the low number of HLA-B27-positive patients with UA, it is unlikely that this would have a substantial effect on a large number of patients.

The number of HLA-B27-positive patients with UA was low but selection of patients with UA on the pattern of the arthritis by itself to test for HLA-B27 (instead of testing all patients with UA) did not increase the percentage of HLA-B27 positivity. These results are in line with other studies that found no association between HLA-B27 and the location of the arthritis ${ }^{7,16}$. The low yield of testing HLA-B27 in patients with UA as a group, but the observation that HLA-B27-positive patients with UA have more SpA features than HLA-B27-negative patients, raises the question of which patients with UA are suitable candidates for HLA-B27 testing.

To our knowledge there are no universally accepted diagnostic criteria for $\mathrm{pSpA}$, but if the goal were to evaluate whether a patient with arthritis could be classified as pSpA, the first step would be to assess whether the criteria are already met with $\mathrm{SpA}$ features readily obtained from the patient's history and physical examination. For example, a patient with arthritis and a preceding infection already fulfills the ASAS pSpA criteria, but a patient with arthritis and a family history does not meet the criteria. But in the latter case, testing positive for HLA-B27 means the arthritis can be classified as pSpA. Thus, HLA-B27 testing in patients with UA is useful only if a patient would meet criteria after testing positive.

\section{REFERENCES}

1. van Tubergen A, Weber U. Diagnosis and classification in spondyloarthritis: identifying a chameleon. Nat Rev Rheumatol 2012;8:253-61.

2. van den Berg R, van Gaalen F, van der Helm-van Mil, Huizinga T, van der Heijde D. Performance of classification criteria for peripheral spondyloarthritis and psoriatic arthritis in the Leiden Early Arthritis cohort. Ann Rheum Dis 2012;71:1366-9.

3. Rudwaleit M, van der Heijde D, Landewe R, Akkoc N, Brandt J, Chou CT, et al. The Assessment of SpondyloArthritis International Society classification criteria for peripheral spondyloarthritis and for spondyloarthritis in general. Ann Rheum Dis 2011;70:25-31.

4. Gran JT, Husby G. HLA-B27 and spondyloarthropathy: value for early diagnosis? J Med Genet 1995;32:497-501

5. Olivieri I, Sarzi-Puttini P, Bugatti S, Atzeni F, D’Angelo S, Caporali R. Early treatment in early undifferentiated arthritis. Autoimmun Rev 2012;11:589-92.

6. Verpoort KN, van Dongen H, Allaart CF, Toes RE, Breedveld FC, Huizinga TW. Undifferentiated arthritis - disease course assessed in several inception cohorts. Clin Exp Rheumatol 2004;22 Suppl 35:S12-17.

7. El-Gabalawy HS, Goldbach-Mansky R, Smith D, Arayssi T, Bale S, Gulko P, et al. Association of HLA alleles and clinical features in patients with synovitis of recent onset. Arthritis Rheum 1999;42:1696-705.

8. Machado P, Castrejon I, Katchamart W, Koevoets R, Kuriya B, Schoels M, et al. Multinational evidence-based recommendations on how to investigate and follow-up undifferentiated peripheral inflammatory arthritis: integrating systematic literature research and expert opinion of a broad international panel of rheumatologists in the 3E Initiative. Ann Rheum Dis 2011;70:15-24.

9. de Rooy DP, van der Linden MP, Knevel R, Huizinga TW, van der Helm-van Mil AH. Predicting arthritis outcomes - what can be learned from the Leiden Early Arthritis Clinic? Rheumatology 2011;50:93-100.

10. Voorter CE, Swelsen WT, van den Berg-Loonen EM. B*27 in molecular diagnostics: impact of new alleles and polymorphism outside exons 2 and 3. Tissue Antigens 2002;60:25-35.

11. van Gaalen FA, Verduijn W, Roelen DL, Bohringer S, Huizinga TW, van der Heijde DM, et al. Epistasis between two HLA antigens defines a subset of individuals at a very high risk for ankylosing spondylitis. Ann Rheum Dis 2013;72:974-8.

12. Amor B, Dougados M, Mijiyawa M. [Classification criteria of spondyloarthropathies]. [Article in French] Rev Rhum Mal Osteoartic 1990;57:85-9.

13. Dougados M, van der Linden S, Juhlin R, Huitfeldt B, Amor B, Calin A, et al. The European Spondylarthropathy Study Group preliminary criteria for the classification of spondylarthropathy. Arthritis Rheum 1991;34:1218-27.

14. Taylor W, Gladman D, Helliwell P, Marchesoni A, Mease P, Mielants H. Classification criteria for psoriatic arthritis: development of new criteria from a large international study. Arthritis Rheum 2006;54:2665-73.

15. Krabben A, Huizinga TW, van der Helm-van Mil AH. Undifferentiated arthritis characteristics and outcomes when applying the 2010 and 1987 criteria for rheumatoid arthritis. Ann Rheum Dis 2012;71:238-41.

16. Kvien TK, Glennas A, Melby K, Granfors K, Andrup O, Karstensen $\mathrm{B}$, et al. Reactive arthritis: incidence, triggering agents and clinical presentation. J Rheumatol 1994;21:115-22.

Personal non-commercial use only. The Journal of Rheumatology Copyright (C) 2014. All rights reserved 